\title{
Crystal Structure and Stereochemistry of the Cyclic Tetramer Derived from Epichlorohydrin
}

\author{
Takatoshi MrYASAKA and Sanae TANAKA \\ Department of Industrial Chemistry, Faculty of Engineering, \\ Tokai University, Hiratsuka, Kanagawa, 259-12, Japan \\ (Received November 4, 1983)

\begin{abstract}
KEY WORDS Cationic Oligomerization / Epichlorohydrin / Boron Trifluoride Etherate / Cyclic Tetramer / $(2 R, 5 R, 8 S, 11 S)-2,5,8,11$ Tetrachloromethyl-1,4,7,10-tetraoxacyclododecane / X-Ray Crystallography /
\end{abstract}

Cationic oligomerization of epichlorohydrin $(\mathrm{ECH})$ is known to produce mainly cyclic tetramers. ${ }^{1-3}$ One of the tetramers, mp 136$136.5^{\circ} \mathrm{C}$, has a generalized structure (1), but it is not known which of four structural (headto-tail, head-to-head etc.) and twenty-three geometrical (cis, trans) isomers represents its fine structure. Ito et al. ${ }^{3}$ have reported that all the trans or cis configurations may be representative on the basis of its simplicity shown by NMR spectra.

An attempt was made to clarify the fine structure of this tetramer, expecting it to possibly be a key substance in synthesizing complicated crown ethers. X-Ray crystallography showed this crystal to have the following absolute structure (Figure 1).

\section{EXPERIMENTAL}

Boron trifluoride diethyl etherate $\left(\mathrm{BF}_{3} \mathrm{OEt}_{2}\right)$ and boron trifluoride diacetate $\left(\mathrm{BF}_{3} 2 \mathrm{CH}_{3}\right.$ $\left.\mathrm{CO}_{2} \mathrm{H}\right)$ were used after distillation. Solvents were purified by conventional methods.

The oligomerization reaction was carried out by the dropwise addition of benzene solution of the initiator $\left(\mathrm{BF}_{3} \mathrm{OEt}_{2}\right.$ or $\left.\mathrm{BF}_{3} 2 \mathrm{CH}_{3} \mathrm{CO}_{2} \mathrm{H}\right)$ to the benzene solution of $\mathrm{ECH}(250 \mathrm{ml}$ in $100 \mathrm{ml}$ of benzene), with stir-

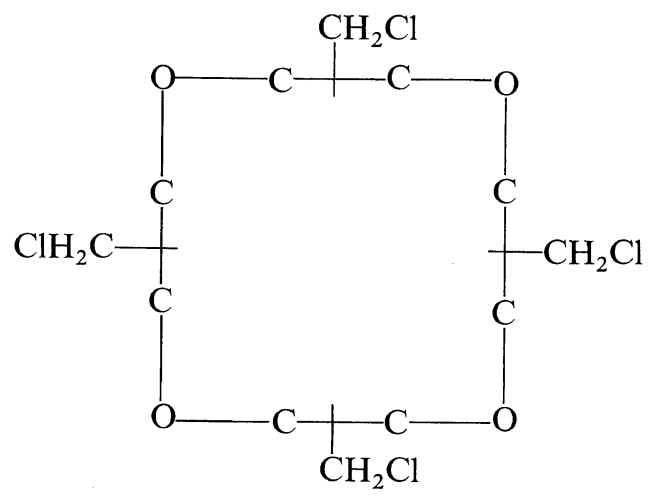

(1)

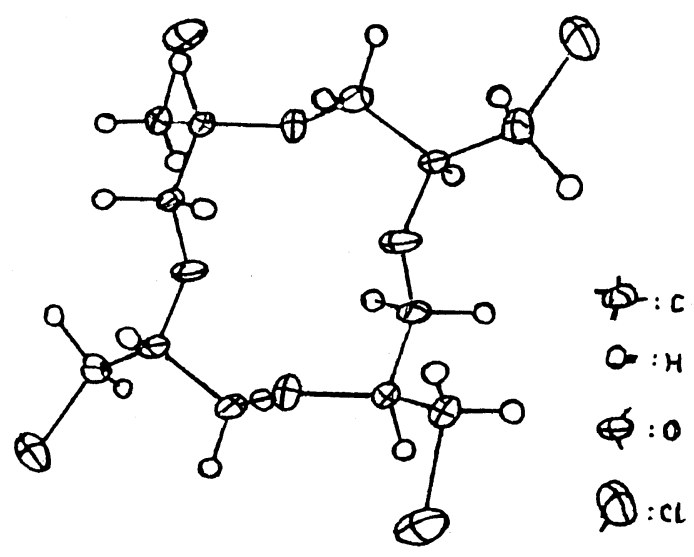

Figure 1. X-Ray crystal structure of the cyclic tetramer of $\mathrm{ECH}$. 
ring at reaction temperature maintained at 0 $60^{\circ} \mathrm{C}$. The reaction mixture was then stirred for additional thirty minutes at the same temperature. The reaction was terminated with a $10 \%$ aqueous $\mathrm{NaOH}$ solution at room temperature and the product was washed with water. Solvent (benzene) and the unreacted $\mathrm{ECH}$ were distilled under reduced pressure $\left(20 \mathrm{mmHg}, 20^{\circ} \mathrm{C}\right)$. Product distribution of the residue was determined by GPC. The viscous residue was extracted with ligroin (bp below $90^{\circ} \mathrm{C}$ ) and the solution was allowed to stand for a long time until crystals formed. Repeated recrystallization from ligroin gave colorless needles, $\mathrm{mp} 136-136.5^{\circ} \mathrm{C}$.

${ }^{1} \mathrm{H}$ NMR $\left(\mathrm{CDCl}_{3}\right) . \delta 3.5,3.55,3.65,3.68$, 3.76, 3.87-3.95, 3.99-4.05. Mass spectrum $m / z 369,370,371,372,373$. Anal. Calcd. for $\left(\mathrm{C}_{3} \mathrm{H}_{5} \mathrm{ClO}\right)_{4}: \quad \mathrm{C}, \quad 39.03 \% ; \quad \mathrm{H}, \quad 5.42 \% ; \mathrm{Cl}$, $38.20 \%$. Found: C, $39.16 \% ; \mathrm{H}, 5.45 \% ; \mathrm{Cl}$, $37.59 \%$.

Product distribution was determined by GPC, using Toyo Soda HLC-802 equipped with Column TSK Gel G2000 H8 (column size $7.5 \mathrm{~mm} \mathrm{ID} \times 60 \mathrm{~cm} \times 2$ ), and eluting with chloroform at $40^{\circ} \mathrm{C}$. The sample concentration was $5 \mathrm{mg} \mathrm{ml}^{-1}$ and flow rate, $0.93 \mathrm{ml} \mathrm{min}^{-1}$. The molecular weight of the tetramer separated by GPC was determined by mass spectrum. The molecular weight of the other oligomers were decided on the basis of a comparison with that of the former. Semilogarithmic plots of the molecular weight against elution volume in GPC gave a straight line. The pentamer and the higher oligomers peak intensities per unit weight relative to tetramer were assumed to be 1.0 , and so consequently weight percent of each oligomer was calculated from its peak area, since dimer and trimer were not detected in GPC chromatograms.

$\mathrm{X}$-Ray crystallography was carried out as follows. A crystal, $0.7 \times 0.3 \times 0.2 \mathrm{~mm}$, was mounted on a Enraf Nonius CAD 4 diffractometer. The lattice constant was measured with $\mathrm{Cu} K \alpha$ radiation (graphite crystal monochromator, $\lambda=1.5405 \AA$ ), and then refined by the least-squares method. The location of nonhydrogen atoms in the structure was determined by a direct method, using the computer program MULTAN. All hydrogen atoms were located on difference Fourier maps.

\section{RESULTS AND DISCUSSION}

\section{Effects of Reaction Conditions of Oligomeri- zation on Product Distribution}

The use of different initiators and variation in reaction temperature and reaction time had no significant effect on product distribution. The results are shown in Table I. Production of dimer, trimer and high polymers could not be detected in all cases. A typical example of product distribution is shown in Figure 2.

Table I. Product distribution of ECH oligomerization ${ }^{\text {a }}$

\begin{tabular}{|c|c|c|c|c|c|c|c|c|c|}
\hline \multirow{2}{*}{ Initiator } & \multirow{2}{*}{ Solvent } & \multirow{2}{*}{$\frac{\text { Temp }}{{ }^{\circ} \mathrm{C}}$} & \multirow{2}{*}{$\frac{\text { Time }}{\mathrm{h}}$} & \multirow{2}{*}{$\frac{\text { Yield }}{w t \%}$} & \multicolumn{5}{|c|}{ Product distribution $/ \mathrm{wt} \%$} \\
\hline & & & & & $n=4$ & $n=5$ & $n=6$ & $n=7$ & $n \geqq 8$ \\
\hline A-1 $\mathrm{BF}_{3} \mathrm{O}\left(\mathrm{Et}_{2}\right)$ & Benzene & 10 & 2 & 20.8 & 36 & 20 & 8 & 8 & 28 \\
\hline A-2 & & 20 & 0.5 & 20.3 & 37 & 24 & 9 & 8 & 22 \\
\hline A-3 & & 60 & 2 & 12.3 & 41 & 28 & 11 & 7 & 13 \\
\hline $\mathrm{B}-1 \mathrm{BF}_{3} \mathrm{AcOH}$ & Benzene & 10 & 2 & 28.8 & 31 & 21 & 9 & 8 & 31 \\
\hline B-2 & & 20 & 2 & 21.7 & 42 & 24 & 10 & 7 & 17 \\
\hline B-3 & & 60 & 2 & 16.1 & 38 & 26 & 21 & 6 & 9 \\
\hline
\end{tabular}

a Overall monomer concentration: $9.1 \mathrm{moll}^{-1}$.

Overall initiator concentration: A, $6.3 \mathrm{mmoll}^{-1}$; $\mathrm{B}, 7.2 \mathrm{mmoll}^{-1}$. 
Crystal Structure and Sterochemistry of the Cyclic Tetramer

Table II. Bond distance and angle calculation

\begin{tabular}{|c|c|c|c|c|c|c|c|c|c|c|c|c|c|}
\hline \multirow[b]{2}{*}{ A } & \multirow[b]{2}{*}{$\mathrm{A}-\mathrm{B}$} & \multirow[b]{2}{*}{ B } & \multicolumn{2}{|c|}{$D_{\max }=1.850$} & \multicolumn{6}{|c|}{$D_{\min }=0.600$ from atom No. 1 to atom No. 20} & \multirow[b]{2}{*}{$\mathrm{C}$} & \multirow[b]{2}{*}{ A-B-C } & \multirow[b]{2}{*}{$A-C$} \\
\hline & & & $\mathrm{B}-\mathrm{C}$ & $\mathrm{C}$ & A-B-C & A-C & A & $\mathrm{A}-\mathrm{B}$ & B & B-C & & & \\
\hline $\mathrm{Cl}_{1}$ & 1.787 & $\mathrm{C}_{1}$ & 1.522 & $\mathrm{C}_{2}$ & 110.0 & 2.73 & $\mathrm{Cl}_{1}$ & 1.787 & $\mathrm{C}_{1}$ & 0.974 & $\mathrm{H}_{11}$ & 102.9 & 2.22 \\
\hline $\mathrm{C}_{2}$ & 1.522 & $\mathrm{C}_{1}$ & 0.974 & $\mathrm{H}_{11}$ & 118.1 & 2.16 & $\mathrm{C}_{2}$ & 1.522 & $\mathrm{C}_{1}$ & 0.923 & $\mathrm{H}_{12}$ & 110.7 & 2.04 \\
\hline $\mathrm{C}_{1}$ & 1.522 & $\mathrm{C}_{2}$ & 1.425 & $\mathrm{O}_{3}$ & 106.8 & 2.37 & $\mathrm{C}_{1}$ & 1.522 & $\mathrm{C}_{2}$ & 1.514 & $\mathrm{C}_{7}$ & 110.9 & 2.50 \\
\hline $\mathrm{O}_{3}$ & 1.425 & $\mathrm{C}_{2}$ & 1.514 & $\mathrm{C}_{7}$ & 111.4 & 2.43 & $\mathrm{O}_{3}$ & 1.425 & $\mathrm{C}_{2}$ & 1.139 & $\mathrm{H}_{2}$ & 112.2 & 2.13 \\
\hline $\mathrm{C}_{2}$ & 1.425 & $\mathrm{O}_{3}$ & 1.426 & $\mathrm{C}_{4}$ & 114.3 & 2.40 & & & & & & & \\
\hline $\mathrm{O}_{3}$ & 1.426 & $\mathrm{C}_{4}$ & 1.512 & $\mathrm{C}_{5}$ & 108.7 & 2.39 & $\mathrm{O}_{3}$ & 1.426 & $\mathrm{C}_{4}$ & 1.055 & $\mathrm{H}_{41}$ & 111.0 & 2.05 \\
\hline $\mathrm{C}_{5}$ & 1.512 & $\mathrm{C}_{4}$ & 1.055 & $\mathbf{H}_{41}$ & 114.2 & 2.17 & $\mathrm{C}_{5}$ & 1.512 & $\mathrm{C}_{4}$ & 1.046 & $\mathrm{H}_{42}$ & 104.5 & 2.04 \\
\hline $\mathrm{C}_{4}$ & 1.512 & $\mathrm{C}_{5}$ & 1.424 & $\mathrm{O}_{6}$ & 108.7 & 2.39 & $\mathrm{C}_{4}$ & 1.512 & $\mathrm{C}_{5}$ & 1.512 & $\mathrm{C}_{8}$ & 112.0 & 2.51 \\
\hline $\mathrm{O}_{6}$ & 1.424 & $\mathrm{C}_{5}$ & 1.512 & $\mathrm{C}_{8}$ & 106.5 & 2.35 & $\mathrm{O}_{6}$ & 1.424 & $\mathrm{C}_{5}$ & 1.113 & $\mathrm{H}_{5}$ & 109.1 & 2.08 \\
\hline $\mathrm{C}_{5}$ & 1.424 & $\mathrm{O}_{6}$ & 1.411 & $\mathrm{C}_{7}$ & 113.7 & 2.37 & & & & & & & \\
\hline $\mathrm{C}_{2}$ & 1.514 & $\mathrm{C}_{7}$ & 1.411 & $\mathrm{O}_{6}$ & 109.3 & 2.39 & $\mathrm{C}_{2}$ & 1.514 & $\mathrm{C}_{7}$ & 1.193 & $\mathrm{H}_{71}$ & 113.4 & 2.27 \\
\hline $\mathrm{O}_{6}$ & 1.411 & $\mathrm{C}_{7}$ & 1.193 & $\mathrm{H}_{71}$ & 107.4 & 2.18 & $\mathrm{O}_{6}$ & 1.411 & $\mathrm{C}_{7}$ & 1.093 & $\mathrm{H}_{72}$ & 111.8 & 2.08 \\
\hline $\mathrm{C}_{5}$ & 1.512 & $\mathrm{C}_{8}$ & 1.793 & $\mathrm{Cl}_{2}$ & 110.9 & 2.73 & $\mathrm{C}_{5}$ & 1.512 & $\mathrm{C}_{8}$ & 1.156 & $\mathrm{H}_{81}$ & 105.1 & 2.13 \\
\hline $\mathrm{Cl}_{2}$ & 1.793 & $\mathrm{C}_{8}$ & 1.156 & $\mathrm{H}_{81}$ & 110.0 & 2.44 & $\mathrm{Cl}_{2}$ & 1.793 & $\mathrm{C}_{8}$ & 1.895 & $\mathrm{H}_{82}$ & 104.1 & 2.32 \\
\hline $\mathrm{C}_{1}$ & 0.974 & $\mathrm{H}_{11}$ & 1.532 & $\mathrm{H}_{12}$ & 35.0 & 0.92 & & & & & & & \\
\hline \multirow[t]{2}{*}{$\mathrm{C}_{1}$} & 0.523 & $\mathrm{H}_{12}$ & 1.532 & $\mathrm{H}_{11}$ & 37.3 & 0.97 & $\mathrm{O}_{3}$ & 1.426 & $\mathrm{C}_{4}$ & 1.046 & $\mathrm{H}_{42}$ & 114.5 & 2.09 \\
\hline & 1055 & $\mathrm{H}_{4}$ & 1653 & $\mathrm{H}_{4}$ & 37.9 & 1.05 & $\mathrm{H}_{41}$ & 1.055 & $\mathrm{C}_{4}$ & 1.046 & $\mathrm{H}_{42}$ & 103.8 & 1.65 \\
\hline $\mathrm{C}_{4}$ & 1.000 & $N_{41}$ & & $N_{42}$ & & & $\mathrm{C}_{4}$ & 1.512 & $\mathrm{C}_{5}$ & 1.113 & $\mathrm{H}_{5}$ & 107.6 & 2.13 \\
\hline $\mathrm{C}_{4}$ & 1.946 & $\mathrm{H}_{42}$ & 1.653 & $\mathrm{H}_{41}$ & 30.4 & 1.85 & $\mathrm{C}_{8}$ & 1.512 & $\mathrm{C}_{5}$ & 1.113 & $\mathrm{H}_{5}$ & 112.8 & 2.28 \\
\hline $\mathrm{C}_{7}$ & 1.193 & $\mathrm{H}_{71}$ & 1.746 & $\mathrm{H}_{72}$ & 38.2 & 1.09 & & & & & & & \\
\hline \multirow[t]{2}{*}{$\mathrm{C}_{7}$} & 1.093 & $\mathrm{H}_{72}$ & 1.746 & $\mathrm{H}_{71}$ & 42.4 & 1.19 & $\mathrm{C}_{2}$ & 1.514 & $\mathrm{C}_{7}$ & 1.093 & $\mathrm{H}_{72}$ & 114.9 & 2.21 \\
\hline & & & & & & & $\mathrm{H}_{71}$ & 1.193 & $\mathrm{C}_{7}$ & 1.093 & $\mathrm{H}_{72}$ & 99.5 & 1.75 \\
\hline $\mathrm{Cl}_{1}$ & 1.787 & $\mathrm{C}_{1}$ & 0.923 & $\mathrm{H}_{12}$ & 105.9 & 2.22 & & & & & & & \\
\hline \multirow[t]{2}{*}{$\mathrm{H}_{11}$} & 0.574 & $\mathrm{C}_{1}$ & 0.523 & $\mathrm{H}_{12}$ & 107.7 & 1.53 & $\mathrm{C}_{5}$ & 1.512 & $\mathrm{C}_{8}$ & 1.095 & $\mathrm{H}_{82}$ & 112.1 & 2.17 \\
\hline & & & & & & & $\mathrm{H}_{81}$ & 1.156 & $\mathrm{C}_{8}$ & 1.095 & $\mathrm{H}_{82}$ & 114.7 & 1.90 \\
\hline $\mathrm{C}_{1}$ & 1.522 & $\mathrm{C}_{2}$ & 1.139 & $\mathrm{H}_{2}$ & 103.3 & 2.10 & & & & & & & \\
\hline $\mathrm{C}_{7}$ & 1.514 & $\mathrm{C}_{2}$ & 1.139 & $\mathrm{H}_{2}$ & 111.9 & 2.21 & & & & & & & \\
\hline
\end{tabular}

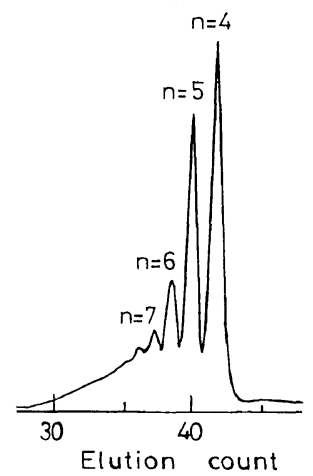

Figure 2. Typical GPC chromatogram of the product from $\mathrm{ECH}$ oligomerization (Experimental No. B-3 in Table I).

Configuration about the Asymmetric Carbons in the Cyclic Tetramer

The structure of the tetramer was estab-

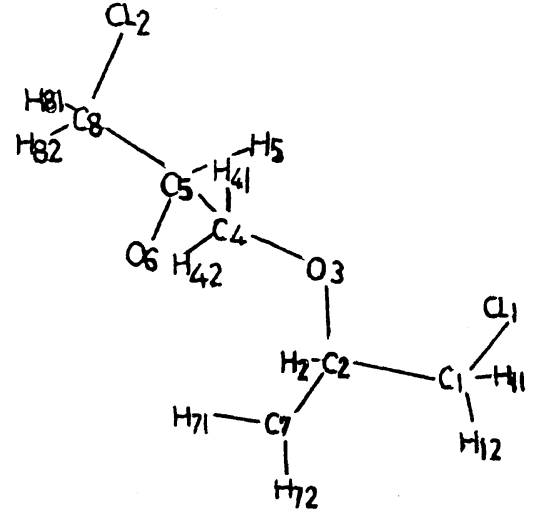

Figure 3. Project view from X-ray analysis of the cyclic tetramer of $\mathrm{ECH}$.

lished as $(2 R, 5 R, 8 S, 11 S)$-2,5,8,11-tetrachloromethyl-1,4,7,10-tetraoxacyclododecane (Figure 1). That is, the ring opening oligomer 
Table III. Crystal data

\begin{tabular}{ll}
\hline Mol formula & $\mathrm{C}_{12} \mathrm{H}_{20} \mathrm{O}_{4} \mathrm{Cl}_{4}$ \\
Crystal system & monoclinic \\
Space group & $\mathrm{P} 2{ }_{1} / \mathrm{a} Z=2$ \\
$a, \AA$ & $9.545(4)$ \\
$b, \AA$ & $10.389(3)$ \\
$c, \AA$ & $8.615(1)$ \\
$\beta$, deg & $111.87(3)$ \\
$V$ calcd,$\AA^{3}$ & 792.9 \\
$D$ calcd $\mathrm{g} \cdot \mathrm{cm}^{-3}$ & 1.550 \\
$F(000)$ & 384 \\
$\mu(\mathrm{Cu} K \alpha), \mathrm{cm}^{-1}$ & 68.5 \\
\hline
\end{tabular}

was formed in a "head-to-tail" sequence and the configuration about the asymmetric carbon was $R-R-S-S$. The bond lengths and angles by X-ray analysis are shown in Figure 3 and Table II and crystal data, in Table III.

\section{Conformation of Cyclic Tetramer}

Conformation of the tetramer is shown in Figure 4.

Although there are no analysis data on the

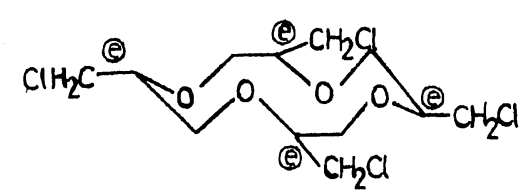

Figure 4. Schematic representation of side chain conformation.

conformation of tetraoxacyclododecane, there are equatorial and axial conformations of cyclooctane $^{4}$ and cyclodecane ${ }^{5}$ like cyclohexane. The equatorial conformation has been reported to be a few $\mathrm{kcal} \mathrm{mol}^{-1}$ or several tens of $\mathrm{kcal} \mathrm{mol}^{-1}$ more stable than the axial conformation in cyclohexane derivatives. ${ }^{6}$ The "equatorial" conformation may possibly be more stable in a twelve-membered ring con $^{9}$ taining four oxygen atoms.

As possible configurations of cyclic tetramers obtained from racemic $\mathrm{ECH}$, the following four diastereomers may be considered.

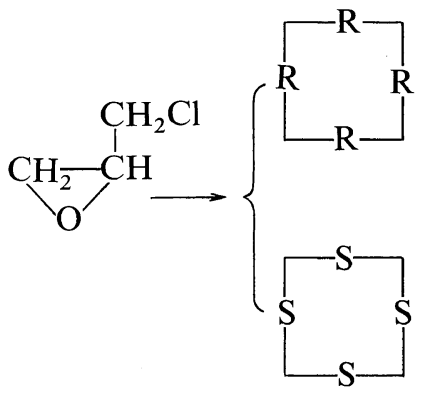

(A)<smiles>[R]CSCCCCSCSC[R]</smiles>

(B)<smiles>[R]CSC[R]</smiles><smiles>[R]CSCSC[R]</smiles>

(C)

(D)
The configuration of the cyclic tetramer, $\mathrm{mp}$ $136-136.5^{\circ} \mathrm{C}$, is (D), and the four side chain $\left(-\mathrm{CH}_{2} \mathrm{Cl}\right)$ conformations are all "equatorial." It is the most thermodynamically stable and symmetrical because of the point of symmetry.

\section{Mechanism of Oligomerization}

Cationic oligomerization of epoxide ring is said to proceed by "back-biting" reaction of growing polymer. ${ }^{7,8}$ In the growing step, whether stereospecific control occurs or not is still not clear.

The only one tetramer of $\mathrm{ECH}$, the absolute structure of which was clarified by the authors, was assumed to be produced by "thermodynamic control." It has the most thermodynamically stable all "equatorial" conformation with the configuration of $R-R-S-S$. This is supported by the molecular model in which no other diastereomers (A, B, and C) have the all "equatorial" conformation. 


\section{REFERENCES}

1. R. J. Kern, J. Org. Chem., 33, 384 (1968).

2. M. G. Zelenskaya, F. L. Kolondkin, F. P. Sidel'kovskaya, and V. A. Ponomarenko, Izv. Akad. Nauk SSSR, Ser. Khim, 5, 1105 (1968); Chem. Abstr., 69, 36670g (1968).

3. K. Ito, N. Usami, and Y. Yamashita, Polym. J., 11, 171 (1979).

4. F. A. Anet and M. S. Jacques, J. Am. Chem. Soc., 88,
2586 (1966).

5. E. Huber-Buser and J. D. Dunitz, Helv. Chim. Acta, 44, 2027, 2033 (1961); ibid., 47, 951 (1964).

6. S. Winstein and N. J. Holnes, J. Am. Chem. Soc., 77, 5562 (1955).

7. E. J. Goethals, Pure Appl. Chem., 48, 335 (1976).

8. S. Inoue and T. Aida, "Cyclic Ethers" in Ring Opening Polymerization, Vol. I, K. J. Ivin and T. Saegusa, Ed., Applied Science Publishers, New York, N. Y., 1984. 